\title{
A CULTURA COMO HOLISMO: GRANDES DIVISÕES ESPACIAIS DO MUNDO NA PESQUISA GEOGRÁFICA GERMANÓFONA
}

\author{
JÖRG SCHEFFER ${ }^{1}$ \\ Universidade Passau \\ Alemanha
}

Desde sempre foi uma preocupação da Geografia dividir a Terra em unidades diferenciáveis e cujas características pudessem ser descritas e analisadas de maneira lógica dentro de um quadro bem delimitado. Com essa divisão e denominação são colocadas à disposição, simultaneamente, propostas de orientação dentro de um mundo per se não-delimitado e nãodenominado. Uma vez que essas divisões marcam a visão de mundo individual com atribuições, delimitações, representação, marginalização ou uniformização, os agentes da criação e disseminação dessas visões de mundo têm uma grande responsabilidade.

No passado, a Geografia realizava divisões do mundo freqüentemente pautadas por características culturais. Se se compreende por "cultura" o padrão de pensamento e ação compartilhado por uma coletividade, isto significa que amplos discursos estão ligados a cada apresentação espacial da cultura, assim, as características fundamentais de uma comunidade humana são ilustradas e classificadas. Desse modo, a cultura pode ser utilizada para a explicação dos fenômenos políticos no entorno dessa comunidade; ela pode ser empregada para a análise de conflitos, pode explicar transformações sociais ou desenvolvimento econômico. Com essa abrangente representação e avaliação há também sempre o perigo de abuso e de instrumentalização (política). Um efeito específico é atribuído ao espaço cultural indicado. Com isso, os limites de um espaço cultural determinados pelo autor adquirem um peso especial. $\mathrm{Na}$ seqüência, será mostrado, com base nos clássicos conceitos de espaço cultural (Kulturraum) dos geógrafos alemães, como, no decorrer do último

\footnotetext{
${ }^{1}$ Jörg Scheffer é doutor em Geografia Humana pela Universität Würzburg e atualmente trabalha como professor assistente na cátedra de Geografia Humana da Universität Passau junto ao Prof. Dr. Ernst Struck, com quem realiza sua Habilitation. Tradução: Leonardo Arantes, mestrando do Programa de Pós-Graduação em Geografia da Universidade Federal Fluminense e bolsista CAPES.
} 
século, a visão de mundo pôde ser influenciada pelas representações do espaço cultural. Trata-se, com isso, principalmente, dos meios formais e dos critérios que são utilizados para a divisão do mundo. Em todas as divisões do mundo relacionadas à cultura, reconhece-se que seus autores se orientam por aspectos culturais individuais (língua, religião, etc), no entanto, entendem a totalidade dos espaços apresentados como cultura. Uma tal "concepção absolutista" das diferenças culturais continua ainda ancorada em nosso pensamento. De diferenças singulares perceptíveis - a conhecida divisão do mundo de Samuel Huntington mostrou isso também - podem ser deduzidas profundas delimitações. Pequenas diferenças são exageradas como uma alteridade geral e características culturais comuns são ofuscadas.

\section{As divisões do mundo sob o signo da geografia regional (até 1950)}

Remontam aos primórdios da geografia científica as divisões do mundo que levam em consideração os marcos culturais, na concepção mais geral de cultura enquanto expressão de atitudes, valores, significações ou atividades comunitários. Com isso, portanto, a "cultura" não constitui, em primeiro lugar, o marco determinante da divisão, mas sim é simplesmente mais um aspecto considerado de um espaço delimitado somente por características físico-geográficas. Essa hierarquia deve-se à posição da geografia regional (Länderkunde) que se consolidava gradualmente por volta do final do séc. XIX na Alemanha. Assim, tratava-se de se identificar limites "naturais" e com isso descobrir (grandes)-espaços [(Groß-)Räume] individualizados e pré-estabelecidos pela natureza. Desse modo, em cada grande-espaço (Land/país), a complexidade especial de suas conexões internas deve ser caracterizada primeiramente pelos fatores abióticos (HETTNER: 1907; 1908). Somente por volta do fim do período imperial alemão, os aspectos antropogeográficos e com isso os marcos culturais em especial influenciaram de modo mais acentuado o paradigma da geografia clássica ${ }^{2}$. Elaboradas entre 1912 e 1939, na Alemanha, as concepções de Banse, Hettner e Schmitthener já apresentam divisões do mundo que, sem renunciar inteiramente à orientação por características naturais, conferem uma posição central à cultura enquanto critério de divisão do mundo.

Uma das primeiras divisões do mundo baseada na cultura foi realizada por Ewald Banse (1883-1953). Por meio da identificação de "Milieus" - que abrangem "não só as particularidades e especificidades compreensíveis e visíveis de uma parte da Terra, mas, além disso, e a elas

\footnotetext{
${ }^{2}$ Para uma visão mais abrangente, ver Böge, 1997; Schulz, 1980:197...
} 
intimamente ligadas, as características espirituais ${ }^{3}$ e sensíveis (...)" - Banse chega a uma divisão de 14 "continentes naturais" (BANSE, 1912:1). Todavia, o autor fica devendo, de algum modo, uma descrição diferenciada dessas características, bem como uma escolha fundamentada em determinados critérios de regionalização. Banse admite, contudo, que sua concepção contém inevitavelmente um "tom pessoal" (BANSE: 1912:131). Com essa confissão sobre a apreensão (predominantemente) subjetiva de seus "continentes", o autor já dá sinais do caráter de constructo das regionalizações futuras.

Enquanto os critérios ainda visíveis, consideravelmente intersubjetivos e imagináveis estavam na base da realização da demanda da Geografia regional de uma apreensão universal das unidades naturais primeiramente mediante características físicas, eles foram modificando-se com a crescente focalização sobre as condições antropogeográficas (culturais) de uma região (Region) e isto levou a novas possibilidades de se estabelecer critérios. A essência determinante de uma grande-região (Großregion) podia então ser extraída de modo parcial e correlacionada adicionalmente com marcos físicos para uma confirmação mútua:

As definições sobre coisas inapreensíveis ("essência", "alma", "espírito", "ambiente") serviam para tornar irrefutáveis o que se sentia e se desejava em relação a um espaço. Mas isso se baseava, freqüentemente, menos em conhecimentos científicos do que, ao contrário, em posições políticas e visões de mundo de cada geógrafo. (BÖGE: 1997:334)

Com a ajuda dessa prática de regionalização podia-se, com intenção política, construir "unidades" homogêneas, implicar cartograficamente alianças e divisões dos Estados ou até mesmo fundamentar justificativas para extensões territoriais. Especialmente a ligação posterior entre cultura, povo ou raça com o ideário geo-darwinistas nos anos 30 e suas decorrentes reivindicações de espaço clarificam, em suas conseqüências devastadoras, o perigo desses tipos de visões de mundo geográficas. (vide SCHULTZ: $1989 ; 2001: 181)$.

${ }^{3}$ (N.T.) O substantivo Geist (espírito) e, por conseguinte, sua adjetivação, geistig (espiritual), possuem uma complexa e polêmica teorização no pensamento filosófico alemão, juntamente com Seele (alma). Preferimos, assim, traduzi-lo em seu sentido estrito e explicá-lo em nota como significando inteligível, mental, assim como fora pensado pela tradição escolástica, que culmina com a divisão kantiana entre "mundo sensível" e "mundo inteligível". 
No exemplo da concepção de Banse pode ser referenciado também o problema da formação de clichês, que também deveria posteriormente acompanhar cada nova regionalização da cultura. Este estava por um lado fundamentado na generalização necessária das diferentes culturas (ou "Milieus"). Pequenas divergências relativas aos marcos considerados abrangentes são com isso automaticamente desconsideradas e generalizações (grosseiras) tornaram-se inevitáveis. Por outro lado, estas generalizações podem ser atribuídas geralmente ao predomínio de um conceito de cultura holístico. Apesar da freqüente divergência entre as representações sobre conteúdos concretos da cultura, predominava, no entanto, o consenso de que a cultura apresenta uma expansão espacial contínua e forma uma totalidade em si homogênea e fechada.

Como essa representação já é própria do tradicional conceito geográfico de regionalização, puderam-se consolidar, sem problemas, delimitações regionais com a integração de cultura. A aceitação de uma homogeneidade interna e de uma alteridade externa ultrapassa com isso claramente em sua capacidade de diferenciação a definição de fronteiras físicas. Junto com a dimensão onde se realizam a definição e a significação, referente à respectiva expansão cultural, o marco de regionalização "cultura" oferecia já cedo, por conseguinte, um meio praticável para uma construção clara da realidade aparente.

Um outro ponto de partida da apresentação espacial das culturas compreendidas regionalmente é apresentada pela conhecida monografia de Alfred Hettner (1859-1941) "A Marcha da Cultura sobre a Terra" (Der Gang der Kultur über die Erde - 1923). Hettner tenta aí explicar, a partir de uma perspectiva histórica, a atual "divisão da cultura e de todos os seus fenômenos singulares sobre a Terra" (HETTNER: 1923:1). Diferentemente da maioria de seus colegas contemporâneos, ele inicia sua obra com uma definição detalhada de cultura: "Utilizo aqui a palavra 'cultura' em seu sentido mais abrangente. Entendo por esta a totalidade da posse de bens materiais e espirituais, assim como as capacidades e formas de organização (...). E não a limito também à oposição entre cultura elevada e os assim chamados povos primitivos (Naturvölkern), e sim a utilizo de modo neutro para os graus elevados e baixos, pois quando se faz um corte nítido entre povos civilizados (Kulturvölkern) e povos primitivos (Naturvölkern), limitando-se a considerar um deles, (...) não se tem uma compreensão do todo" (1923:2). Se se considera, além disso, que Hettner se posiciona ceticamente ante o determinismo biológico de um difundido conceito de raça (1923:7) e confere um desenvolvimento constante aos diferentes níveis culturais de cada cultura (1923:4), então sua determinação de cultura é para aquela época consideravelmente progressista. A caracterização que 
Hettner faz dos diferentes níveis de desenvolvimento cultural fundamentase, no entanto, também em avaliações e valorizações inapropriadas que chamam a atenção especialmente para a problemática de uma comparação cultural.

Na medida em que Hettner, sob sua perspectiva histórica, classifica regiões culturais concretas conforme cada um dos níveis de desenvolvimento por ele considerados, ele cria uma hierarquia valorativa das culturas disseminadas naquelas regiões. Com isso, a descrição e classificação das culturas mencionadas seguem uma direção de desenvolvimento pré-estabelecida rumo ao "mais elevado", cujo ponto final apresenta a cultura européia (1923:44). Uma tal divisão cultural mais baseada numa visão de mundo eurocêntrica - não prevê um desenvolvimento autônomo, não-influenciado pela Europa, de uma "equivalência" cultural.

Além disso, Hettner considera em todas as descrições dos níveis culturais sua "condicionalidade natural", a qual pode obstruir uma europeização de outras culturas. Por outro lado, será acentuada a favorável situação natural da Europa. Assim, por exemplo, a "cultura dos países do Mediterrâneo" adquiriu desde cedo, “... no decorrer do desenvolvimento, devido a outros fundamentos geográficos, características completamente distintas que se diferem daquela [da cultura oriental atual; J. S.] e, sobretudo, da cultura antiga, significando, além disso, um grande progresso; ela apresenta uma forma mais elevada e mais bela da cultura". (1923:33)

A representação geográfico-regional de Hettner de uma unidade espacio-natural e espacio-cultural (vide acima) vigora de modo regulador no que se refere a estes tipos de atribuições culturais; assim, o caráter cultural de uma região é limitado pelo aspecto geográfico-natural, no que diz respeito a sua capacidade de transformação, e pode dificilmente ser alcançado segunda a escala de uma europeização.

A europeização trazida de fora por meio do colonialismo é registrada cartograficamente por Hettner na sua segunda edição de 1929. O eurocentrismo é apresentado aqui em uma visão de mundo que diferencia regiões delimitadas em grandes áreas sob a influência colonial, de acordo com influência cultural (Oeste ou Leste europeu) e tipos de colonização. Além disso, "povos primitivos (Naturvölker) e semi-primitivos (Halbnaturvölker) autônomos" são descritos apenas de modo genérico. A hierarquização das "culturas" é acentuada de modo a valorizar a graduação de símbolos mais claros (povos primitivos e semi-primitivos) a mais escuros (cultura européia ocidental). (HETTNER: 1929:106) Também o 
geógrafo alemão Heinrich Schmitthenner (1887-1957) se vale de argumentação gráfica para sua teoria da cultura (vide imagem 1A).

Fig. 1. Divisões Tradicionais do Mundo (A e B) e Características Individuais Regionalizadas $(C)$

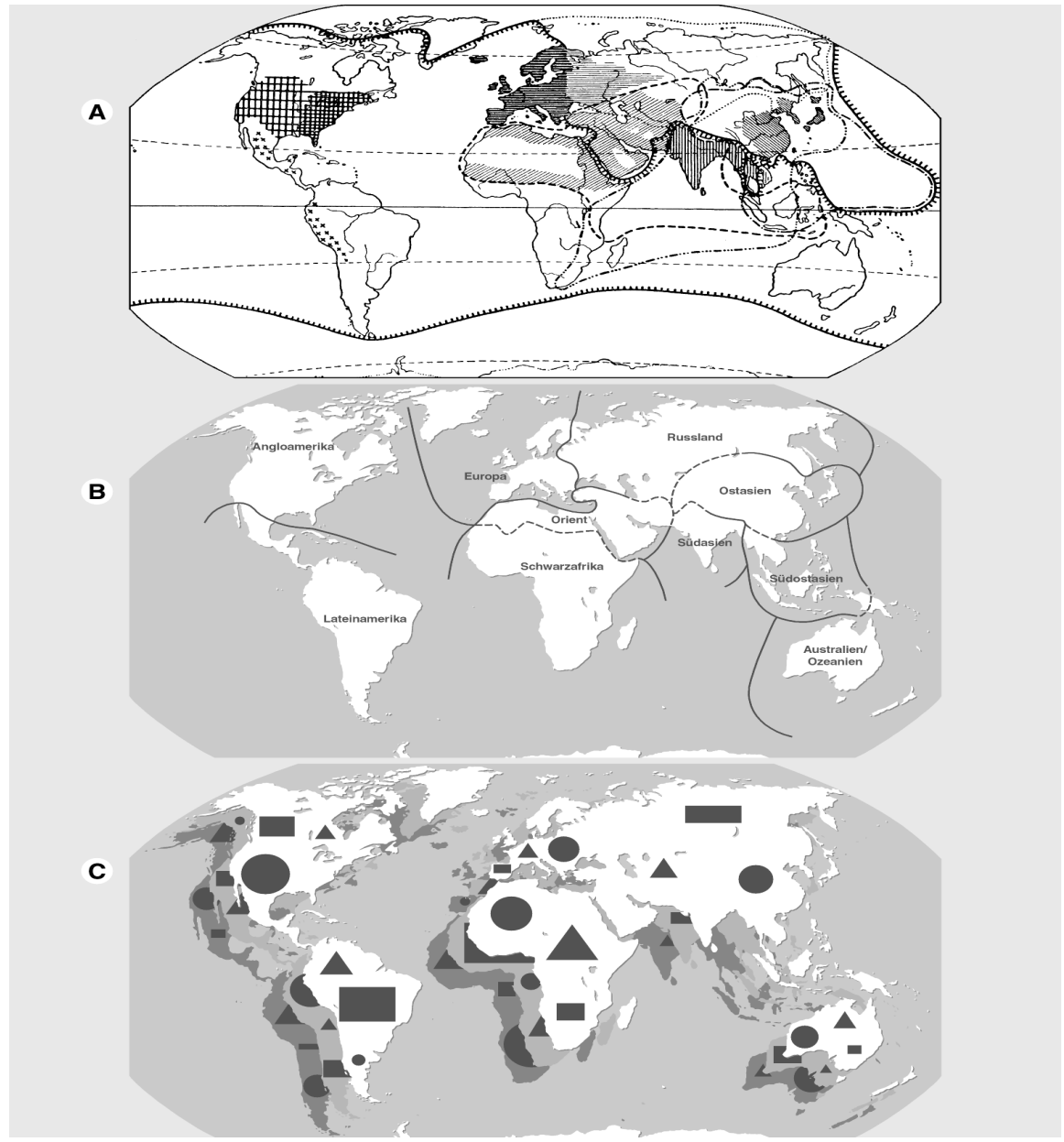

Referenciado em: A - Schmitthenner (1951) e B - Newig (1986)

A obra publicada em 1938 "Espaços Vitais na Luta das Culturas" (Lebensräume im Kampf der Kulturen) divide o mundo em povos ativos, isto é, culturas que se expandem, e aqueles que são passivamente incorporados ou explorados. Segundo Schmitthenner (1938:9), é "imanente 
a cada povo saudável a ambição de expandir-se, pelo menos a todo povo que não está estagnado, e sim se encontra em uma transformação cultural progressiva" (SCHMITTHENNER: 1938:9). Sua regionalização divide cinco culturas superiores ativas da Terra, que abrange: 1. a ocidental (Europa ocidental); 2. a cultura do Leste europeu; 3. a cultura árabe; 4. a cultura indiana; 5. a cultura leste-asiática. Destas - e também do "novo ocidente" (América do Norte) - parte uma opressão crescente às áreas vizinhas e "passivas" (apresentadas em branco e não-denominadas no mapa):

A partir das áreas das grandes culturas superiores, a opressão da população, o declínio econômico e cultural tendem para os espaços pouco habitados e passivos. Cada uma das culturas superiores tem sua própria área de expansão, distribuída, de certo modo conforme o destino, pela posição e componentes naturais. (1938:16)

Aquela "exploração do espaço habitável" da Terra se realiza, segundo Schmitthenner, ao longo das "frentes culturais" - especialmente com o aumento das populações - na luta das culturas. A teoria da luta cultural de Schmitthenner mostra grande proximidade com o conhecido argumento do povo-sem-espaço (Volk-ohne-Raum) do nacionalsocialismo; a expansão espacial e da influência geopolítica-colonial podem, com isso, ser citadas como alastramento "natural" do espaço vital. Diferentemente da visão de mundo darwinista e racial de caráter nacional, Schmitthenner relaciona suas reflexões a unidades espaciais maiores que são identificadas como "culturas superiores".

Para descrição e delimitação das "culturas superiores" recorre-se à característica conectiva de cultura, novamente de modo indefinido e variável. Assim, por exemplo, o "mundo cultural do Leste europeu" equiparado com a Rússia européia-asiática - é esboçado por uma orientação geográfico-regional ("o norte continental da Eurásia. Ela abrange o grande trajeto da formação natural relativamente unitária"). $\mathrm{O}$ "mundo cultural do Leste europeu" é então completado com uma descrição superficial do espaço e do conteúdo da "russidade" ou da essência russa espalhada pela totalidade do grande espaço natural (1938:21...). A “...expansão a Leste, Norte e Sul que faz crescer o espaço do povo russo e que ainda hoje continua a crescer para além do Ural, deu à russidade a incompletude, estados originais quase caóticos" (1938:23). A uniformização do "mundo cultural do Leste europeu" é criado aqui através de características que paradoxalmente compreendem heterogeneidade cultural na forma de caos e incompletude. Com isso, o uso da cultura enquanto característica da regionalização revela mais uma vez o espaço de 
construção de critérios, o qual abre ao autor as mais distintas interpretações do abrangente conceito de cultura.

Também em Schmitthenner fica claramente reconhecível uma perspectiva eurocêntrica. Ela ressalta a degradação dos espaços passivos: "África negra como área de penetração ocidental" (1938:66) ou "Austrália e o mundo insular australiano como área de expansão ocidental” (1938:79), bem como a equiparação de europeização e modernização: "No século XVIII, a Rússia se europeizou como o Japão se europeizou e a China está em vias de se europeizar" (1938:21).

Com base nestas citações, também fica mais uma vez claro como o uso impreciso dos conceitos abstratos "cultura" e "europeização" pode levar a mal-entendidos e contradições. Como se considera Europa ao mesmo tempo a "cultura superior do Ocidente" (ou o "mundo cultural do Leste Europeu"), a europeização implica simultaneamente uma aproximação da cultura russa, japonesa ou chinesa com esta cultura. Isto contradiz afinal a tese principal de Schmitthenner sobre o perigo de uma luta de culturas que, especialmente devido a suas diferenças, formam crescentemente frentes contrárias.

Com essa breve consideração dos três conhecidos conceitos de divisão, foram constatadas várias dificuldades que chamam atenção principalmente para a problemática de uma regionalização da cultura em grandes áreas. Apesar de sua força inspiradora e originalidade na época, eles elucidaram de maneiras distintas os problemas da subjetividade, discriminação, uniformização inadequada, formação de clichês, do eurocentrismo e do perigo de sua instrumentalização (política). Esses conceitos têm em comum o fato de apresentarem constructos dos autores que amalgamam resultados individuais dentro de uma totalidade cultural fictícia, generalizam de modo extremo e avaliam de maneira problemática.

\section{Recentes concepções da divisão do mundo (após 1950)}

Com o título "A Geografia e os Continentes Culturais" (Die Geographie und die Kulturerdteile), Albert Kolb introduziu, em 1962, uma concepção dentro da discussão científica com o objetivo de propor à geografia regional (Länderkunde) de então um conceito antropogeográfico alternativo. Como "as unidades naturais eram vistas simplesmente" enquanto indivíduos espaciais e com isso negligenciava-se as conexões antropogeográficas, a geografia regional pautada pela cultura deveria então entrar "no ramo da geografia humana, ou seja, uma disciplina dos espaços 
culturais determinada pelo Homem e suas atividades" (KOLB, 1962:45). Os limites destes espaços culturais, segundo Kolb, determinam-se "através dos homens, de sua cultura, de suas unidades sociais, de suas criações paisagísticas e de sua história." (1962:46).

Se, com isso, Kolb se distancia expressamente da hipótese da Geografia regional sobre a concordância espacio-cultural e espacio-natural, ele, contudo, inclui a natureza, ainda que parcialmente, na determinação de seus continentes culturais: “...por continente cultural (Kulturerdteil) [entende-se] um espaço de escala subcontinental cuja unidade se baseia na origem individual da cultura, na ligação especial e singular dos elementos culturais e naturais da formação paisagística, na organização espiritual e social autônoma e no contexto histórico" (KOLB, 1962). A partir da combinação dos elementos materiais e imateriais, de sua densidade e expansão, e daqueles seus portadores determina-se, segundo Kolb, a essência dos continentes culturais. Desta forma, podem-se diferenciar ao menos 10 continentes culturais.

Nessa divisão geográfico-cultural do mundo o autor vê a vantagem de poder superar o pensamento relativo a povos e nações. Mais tarde, tratou-se de considerar com mais força aquelas regiões também fora da Europa enquanto espaços culturais e "novas unidades de parceria" e, do ponto de vista da "supressão das distâncias", de se transformar a visão geográfica de mundo com base nos "continentes culturais" (vide 1962:49).

Com isso, o projeto de Kolb mostra grandes divergências com as divisões da Terra de Banse, Hettner e Schmitthenner no que tange ao objetivo. Kolb se diferencia claramente de seus antecessores, especialmente em relação à ambicionada superação do eurocentrismo e à identificação das culturas em grandes áreas, sobretudo enquanto unidades de divisão e pesquisa antropogeográficas (e não basicamente enquanto objeto avaliado e comparativo de validades distintas). Porém, a mencionada divisão do mundo em culturas mostra em outros pontos grande proximidade com essas divisões antigas. Embora Kolb defina o termo "continente cultural" e introduza critérios gerais para a diferenciação desses continentes, toda regionalização baseada nesses critérios permitirá necessariamente as mais diversas interpretações. Pois, por um lado, os seus critérios sugerem novamente uma consideração holística e total que, entre outras coisas, leva em conta a "origem individual da cultura", uma "ordem espiritual e social autônoma" e a "essência" específica de uma região. Uma tal abrangência tem de partir agora, dentro da grande escala espacial, de regiões culturalmente não-influenciadas e em si homogêneas, que afinal de contas não se aplicam a nenhum dos continentes culturais citados. A 
identificação concreta das grandes regiões será caracterizada levando-se em consideração as variações na escala, na delimitação e especialmente na determinação do conteúdo da "essência".

Por outro lado, o conceito de continentes culturais de Kolb admite uma determinação adicional das grandes regiões, que visa à apreensão da distribuição e densidade de cada elemento cultural. Também aqui há espaço para as diferentes possibilidades de interpretação. Ele se refere às seguintes questões: quais elementos culturais (necessariamente à escolha) podem ser considerados; se a cultura pode ser representada então através dessa escolha; e até que ponto os elementos culturais se apresentam dentro da coerência espacial; ou como se pode ficar sabendo sobre esses elementos culturais, por exemplo, enquanto "ordem espiritual". Assim, os continentes culturais apresentam como resultado - com base em dois tipos de consideração que se excluem mutuamente - uma interpretação tosca e simplificadora da realidade cultural entre outras imagináveis.

Kolb também não abdica inteiramente da Geografia da natureza para a fundamentação de seus continentes culturais. Subordinada à argumentação espacio-cultural, a Geografia da natureza encontra naquele conceito sua entrada na Geografia científica, ainda que posteriormente, após a desvalorização política e metodológica da Geografia regional desde o final dos anos $1960 .{ }^{4}$

A aceitação geral de sua divisão de mundo apóia-se principalmente na visão de mundo já estabelecida por seus predecessores. Somente a introdução posterior dos continentes culturais de Kolb no ensino de Geografia e em vários planos escolares alemães levaria, dentro da geografia germanófona, a uma discussão controversa sobre o conceito. Ligado às exposições de Kolb e com base na citada definição de continentes culturais, Jürgen Newig argumenta a favor da introdução nas escolas dos "continentes culturais" independentes política e economicamente. (NEWIG, 1986).

Newig propõe uma concretização dos critérios de divisão, ao contrário de Kolb, na medida em que apresenta cinco características que formam os continentes culturais em "grande área" e "unificados" (1986:264). Estas compreendem: 1. uma diretriz normativa (na maioria das vezes em forma de religião e ideologia); 2. língua, escrita e direito; 3. cor da pele (raça); 4. economia; e 5. situação geográfica. Simultaneamente, o autor admite também que sobre este fundamento, a delimitação dos continentes "...não [poderia] acontecer rigorosamente por via qualitativa,

${ }^{4}$ Vide definição de continente cultural, entre outras, em Kolb, 1987. 
visto que uma parte das características e sobretudo seus entrelaçamentos mútuos são extraídos de uma quantificação" (1986:265).

Dentro desse espaço livre, quase inalterado e empírico, Newig prossegue com os 10 continentes culturais de Kolb, transformando simplesmente as designações (NEWIG, 1986; 2001). A fixação concreta da visão de mundo em "continentes culturais" - pela primeira vez também em forma cartográfica (vide imagem 1B) - e sua determinação definitiva em grandeza e número, forneceram desde então uma ampla base de discussão. A discussão deficitária com o conceito de cultura, a homogeneidade implicada dentro dos espaços culturais delimitados, as dificuldades das delimitações e a adotada permanência espacial e temporal das culturas e dos continentes culturais, foram repetidamente criticadas nesse contexto ${ }^{5}$. Com isso, pode ser salientado como especialmente problemático o fato de Newig praticamente não tematizar esses aspectos. Desse modo, dentro da tradição de Banse, Hettner, Schmitthenner e Kolb, fica estabelecida uma visão de mundo como realidade cultural que oculta amplamente seu caráter de constructo.

Se por um lado se observa de maneira limitada que na determinação e delimitação "sempre fatores de valoração subjetivos [desempenham] um papel importante que não podem ser compreendidos por todos e em toda parte" (NEWIG, 1995:45), por outro, os exemplos de regionalizações culturais divergentes (Huntington, Spencer e Thomas) não mostram fundamentalmente nenhuma outra concepção de regionalização. Assim como em Kolb, a dinâmica cultural na concepção de Newig realiza-se ao longo das frentes culturais e linhas de fronteira (vide NEWIG, 1986:265; KOLB, 1962:47). Especialmente nos últimos tempos, a transformação cultural reconhecida de maneira mais intensa sob o signo da globalização deixa claro que esta representação certamente não pode ser vista a partir das condições atuais.

\section{Divisões do mundo na época da globalização}

Com a globalização, a heterogeneidade cultural parece ter se tornado multiplamente sem distâncias. Os indícios de um cruzamento ou hibridização cultural são adotados pelos críticos para rejeitar basicamente uma delimitação territorial pela cultura. Cada divisão do mundo correspondente tem que levar a uniformizações; ela pode desencadear clichês e preconceitos e contribuir para uma visão unilateral das culturas.

${ }^{5}$ Entre outros por Dürr, 1986; Popp, 2003; Stöbber, 2001; Scheffer, 2006. 
Nesse contexto, também a divisão de mundo de Samuel Huntington é sempre criticada (1993) como constructo unilateral. (Entre outros, Ó TUATHAIL, 1996; REUBER; WOLKERSDORFER, 2002).

Os conceitos atuais compreendem a cultura, ao invés disso, como desterritorializada, desmaterializada e como processo discursivo. Desde que os acessos abstratos às diferenças e diferenciações culturais permitam ainda uma perspectiva espacial, a cultura deve ser compreendida como flows, como travelling culture, como formação com fronteiras crescentes (por exemplo, CLIFFORD, 1992; MASSEY, 1992; MITCHELL, 2003) ou também como rede (CASTELLS, 2006). No ramo dos cultural studies (por exemplo, BACHMANN-MEDICK, 2006) ou de uma "Geografia Cultural Nova" (por exemplo, GEBHARDT et al., 2003), toma-se claramente distância das delimitações nítidas da cultura localizada espacialmente e dos mapas facilmente memorizáveis dos espaços culturais concretos, a partir dos fundamentos citados - por exemplo.

$\mathrm{Na}$ geografia germanófona, foi especialmente Benno Werlen quem chamou atenção para os problemas de uma geografia centrada no espaço (WERLEN, 1995a, 1997). Enquanto ponto crítico central na percepção atual da disciplina, Werlen alega que as atuais sociedades pós-modernas vivem espacialmente desancoradas e cujas características, por isso diferentemente das características materiais - não podem ser mais localizadas claramente. Conseqüentemente, também não é (mais) possível apreender regionalmente sociedades ou culturas. Ao invés disso, o sujeito deve ser colocado (e não mais o espaço), de maneira conseqüente, no centro da consideração, e a constituição do espaço deve ser tematizada no agir cotidiano. "Regionalização" significa agora a ação social "...mediante a qual os sujeitos (agentes) se relacionam com o mundo" (WERLEN: 1997, p.16). Assim como a "história é produzida" no cotidiano por cada sujeito agente, também a geografia se origina do agir humano. Os fatores de influência que estão na base desse "fazer-geografia-cotidiana" devem ser decifrados pela geografia pautada pela teoria da ação: "Deve ser questionado no âmbito de quais premissas do mundo cotidiano, sob a aplicação de qual modus operandi e categorias, as geografias são realizadas" (WERLEN: 1995, p.74).

Com tal ênfase no indivíduo e na recusa de uma apreensão da coletividade, toda estruturação das diferenças culturais torna-se nula. Com certeza, isso tem como conseqüência também o fato de as diferenças interculturais basicamente não poderem mais ser generalizadas. Diferenças que viajantes percebem fora de sua terra natal não podem ser nem compreendidas nem denominadas. Chegar-se-ia sempre - assim deveriam 
objetar os adeptos da geografia pautada pela teoria da ação - a generalizações inadequadas.

Daí resulta uma forte oposição entre, de um lado, aqueles partidários a uma regionalização tradicional, que salientam a importante função de divisão e de orientação agora na época da globalização e, de outro, os partidários das abstratas concepções espacio-culturais, que levam em consideração de modo conseqüente as implicações da globalização.

Essa oposição parece, por isso, especialmente grande, visto que em ambos os lados o discurso continua sendo a cultura num sentido holístico e total. Se os autores - como Newig na tradição das antigas concepções de espaço cultural - identificarem unidades culturais, está então implicada aí uma concordância espacial de todas as características culturais pertencentes a esta unidade.

É fácil para os críticos demonstrarem que a maioria das características culturais (ou mais precisamente: das pessoas que têm essas características) não se enquadram nesses limites pré-estabelecidos. Mas ao invés de investigar essas diferenças culturais singulares, o conceito de cultura regional será rechaçado de modo geral, pois, por fim, os críticos também continuam a pensar a diferença regional de maneira holística. Já que eles não podem propor nenhum padrão de divisão alternativo para as diferenças culturais percebidas, as tradicionais divisões de mundo simplificantes permanecem atrativas na prática cotidiana.

\section{Perspectiva: a superação do paradigma holista enquanto pressuposto para uma regionalização da cultura}

Se aceitarmos que há marcas regionais em um mundo globalizado, então o foco deveria ser direcionado para marcas singulares e não para a cultura enquanto totalidade. Da mesma forma como os mapas lingüísticos dão informações sobre a disseminação dessa característica da cultura, seria igualmente concebível compreender outras características da cultura. Sob o signo da globalização, a cultura enquanto totalidade não está mais ligada territorialmente. Contudo, é evidente a continuação de uma concentração regional de características individuais. No plano da escala local, regional, nacional ou mesmo continental ainda podem, em geral, ser demonstrados padrões de pensamento e ação predominantemente espaciais (vide também HAESBAERT, 2001). De acordo com a seção da característica cultural, podem ser derivadas regiões específicas, que apenas informam sobre a manifestação de uma característica escolhida (Fig. 1C; SCHEFFER, 2007). 
Como resultado, essa concepção de regionalização leva às mais distintas divisões espaciais com finalidades específicas que, dependendo do objetivo (por exemplo, perspectiva ou apresentação detalhada) e das características culturais escolhidas (qual característica possui relevância), podem divergir fortemente das regionalizações culturais tradicionais. Sua grande vantagem diante dessas divisões antigas reside no fato de que, deste modo, as mencionadas dificuldades de uma espacialização cultural são reveladas. Com isso, a determinação, delimitação e generalização necessárias, assim como a dinâmica temporal e espacial da cultura pode se tornar concretamente o tema de uma característica cultural considerada isoladamente e ser colocada para discussão. A problemática das fronteiras absolutas, que o pensamento holístico há mais de 100 anos provoca na geografia, será superada então com a pluralização dos espaços culturais.

\section{A CULTURA COMO HOLISMO: GRANDES DIVISÕES ESPACIAIS DO MUNDO NA PESQUISA GEOGRÁFICA GERMANÓFONA}

Resumo: As divisões do mundo pautadas por marcos culturais têm uma longa tradição na geografia germanófona. Até os dias de hoje, a cultura é conceitualizada como totalidade, o que leva conseqüentemente a que cada divisão absolutize as diferenças culturais. $\mathrm{O}$ artigo descreve esta problemática com base nos conceitos clássicos desde os primórdios da geografia até a geografia do presente. Também para a discussão atual pode-se constatar que a idéia de um conceito holístico de cultura ainda permanece usual e até agora não foi substituída por uma regionalização alternativa. $\mathrm{O}$ artigo conclui com uma sugestão de como esta regionalização alternativa poderia ser na era da globalização.

Palavras-chave: Cultura, divisão do mundo, holismo, globalização, clássicos alemães

\section{CULTURE AS HOLISM: LARGE-SCALE CLASSIFICATION OF THE WORLD IN GERMAN-SPEAKING GEOGRAPHY}

Abstract: Divisions of the world using culture as the defining trait have had a long history in German geography. Until this day, culture is being conceptionalized as a whole, with the consequence that each division poses cultural differences as absolutes. This essay aims to describe the problem by using traditional concepts from the beginning of geography up to the present. Even in the current debate, as will be shown, the idea of a holistic concept of culture is still in use and has not been replaced yet by an alternative form of regionalisation. The article will conclude with a suggestion of what this would look like in the age of globalisation. 
Keywords: Culture, division of the world, holism, globalisation, German classics

\section{BIBLIOGRAFIA}

BACHMANN-MEDICK, D. (2006). Cultural Turns. Neuorientierungen in den Kulturwissenschaften. Hamburg: Rowohlt.

BANSE, E. (1912). Geographie. In: PM 58, p. 1-4.

BÖGE, W. (1997). Die Einteilung der Erde in Großräume. Zum Weltbild der deutschsprachigen Geographie seit 1871. Hamburg: Selbstverlag des Instituts für Geographie.

CASTELLS, E. (1996) The rise of the Network Society. (The information age: Economy, Society and Culture, 1). Oxford: Blackwell.

CLIFFORD, J. (1992). Traveling cultures. In: L. Grossberg, C. Nelson \& P. Treichler (org.): Cultural studies. London: Routledge, p. 96-116.

DÜRR, H. (1987) Kulturerdteile: Eine „neue“ Zehnweltenlehre als Grundlage des Geographieunterrichts? In: Geographische Rundschau 39, Heft 4, p. 229-232.

GEBHARDT, H.; REUBER, P. e WOLKERSDORFER, G. (org.) (2003) Kulturgeographie. Aktuelle Ansätze und Entwicklungen. Heidelberg: Spektrum. HAESBAERT, R. (2001) Le Mythe de la déterritorialisation. In: Géographie et cultures 40.

HETTNER, A. (1907) Grundzüge der Länderkunde. Bd. I. Europa. Leipzig: Spamer.

p. 1-13.

(1908) Die geographische Einteilung der Erdoberfläche. In: GZ 14,

Schriften 1$)$.

(1923) Der Gang der Kultur. Berlin: Teubner (Geographische Teubner.

(1929) Der Gang der Kultur über die Erde. Leipzig e Berlin:

HUNTINGTON, S. (1993) The Clash of Civilisations. In: Foreign Affairs 72, No. 3, p. 22-49.

KOLB, A. (1962). Die Geographie der Kulturerdteile. In: Leidlmair, A. (org.): Hermann von Wissmann-Festschrift. Tübingen: Selbstverlag des Geographischen Instituts, p. 42-49. 
KOLB, A. (1987) Schmitthenners Lebensräume und die Kulturerdteile. In: Blume, H. e Wilhelmy, H. (org.). Heinrich Schmitthenner-Gedächnisschrift. Stuttgart: Selbstverlag des Instituts, p. 97-109.

MASSEY, D. (1992) A place called home? In: New Formations 17, p. 3-15. MITCHELL, K. (2003) Cultural geographies of transnationality. In: Anderson, K., Domosh, M., Pile, S. e N. Thrift (org.). Handbook of cultural geography. London: Thousand Oaks, p. 7487.

NEWIG, J. (1986) Drei Welten oder eine Welt: Die Kulturerdteile. In: Geographische Rundschau 38, Heft 5, p. 262-267.

(1988) Zur Kulturerdteil-Diskussion. Eine abschließende Stellungnahme. In: Geographische Rundschau 40, Heft 10, p. 66-70.

128/1995, p. 44-45.

(1995). Weltordnung nach Kulturerdteilen. In: Geographie heute

Ó TUATAIL, G. (1996) Critical Geopolitics. The politics of writing global space. Minneapolis: Routledge.

POPP, H. (2003) Kulturwelten, Kulturerdteile, Kulturkreise - Zur Beschäftigung der Geographie mit der Gliederung der Erde auf kultureller Grundlage. Ein Weg in die Krise? In: Popp, H. (org.): Das Konzept der Kulturerdteile in der Diskussion - das Beispiel Afrikas. Bayreuth: Verlag Naturwissenschaftliche Gesellschaft, p. 19-42.

REUBER, P. e WOLKERSDORFER, G. (2002) Clash of Civilizations aus Sicht der kritischen Geopolitik. In: Geographische Rundschau 54, Heft 7/8, p. 24-28.

SCHEFFER, J. (2006) Das Kulturraumkonstrukt im Zeichen von Globalisierung und Interkulturalität und seine Bedeutung für einen zeitgemäßen Geographieunterricht. In: E. Kulke, H. Monheim u. P. Wittmann (org.): Grenzwerte. Tagungsbericht und wissenschaftliche Abhandlungen. 55. Trier: Deutscher Geographentag Trier 2005.

(2007) Den Kulturen Raum geben - Das Konzept selektiver Kulturräume am Beispiel des deutsch-tschechisch-österreichischen Dreiländerecks. Passau: Selbstverlag des Fachs Geographie. (Tese de doutorado)

SCHMITTHENNER, H. (1938) Lebensräume im Kampf der Kulturen. Leipzig: Quelle \& Meyer. 
(1951). Lebensräume im Kampf der Kulturen. Heidelberg: Quelle \& Meyer.

SCHULTZ, H.- D. (1980) Die deutschsprachige Geographie von 1800 bis 1970. Ein Beitrag zur Geschichte ihrer Methodologie. Berlin: Selbstverlag des Geographischen Instituts.

(1989) Versuch einer Historisierung der Geographie des Dritten Reiches am Beispiel des geographischen Großraumdenkens. In: Fahlbusch, M.; Rössler, M. e Siegrist, D. (org.): Geographie und Nationalsozialismus. Kassel: Selbstverlag der Universität Kassel, p. 1-75.

(2001) Von der Nationalbildung zur Europaerziehung: Identitätskonstrukte der deutschen Schulgeographie im 19/20 Jahrhundert. In: Geographie und ihre Didaktik, Heft 4, p. 169-197.

STÖBER, G. (2001) „Kulturerdteile“, „Kulturräume“ und die Problematik eines „,räumlichen“ Zugangs zum kulturellen Bereich. In: Stöber, G. (org.) „Fremde Kulturen“ im Geographieunterricht. Analysen - Konzeptionen Erfahrungen. Hannover: Hahnsche Buchhandlung, p. 138-155.

WERLEN, B. (1995a) Sozialgeographie alltäglicher Regionalisierungen. Bd. 1: Zur Ontologie von Gesellschaft und Raum. Stuttgart: Steiner.

(1995b) Von der Regionalgeographie zur Sozial-/Kulturgeographie alltäglicher Regionalisierung. In: Werlen, B. e Wälthy, p. (org.): Kulturen und Raum. Theoretische Ansätze und empirische Kulturforschung in Indonesien. Chur/ Zürich: Rüegger, p. 65-86.

(1997) Sozialgeographie alltäglicher Regionalisierungen. Bd. 2: Globalisierung, Region und Regionalisierung. Stuttgart: Steiner. 